\title{
Effects of biomass pellet composition on the thermal and emissions performances of a TLUD cooking stove
}

\author{
Zhang Zongxi ${ }^{1,2,3}$, Sun Zhenfeng ${ }^{4}$, Zhang Yinghua ${ }^{5}$, Ding Hongyan ${ }^{6}$, Zhou Yuguang ${ }^{1,2,3^{*}}$, \\ Zhang Yixiang ${ }^{1,2,3,7}$, Riaz Ahmad ${ }^{1,2,3}$, Crispin Pemberton-Pigott ${ }^{2,3}$, Dong Renjie (1,2,3 $^{\text {, }}$
}

(1. Bioenergy and Environment Science \& Technology Laboratory, College of Engineering, China Agricultural University, Beijing 100083, China; 2. Key Laboratory of Clean Production and Utilization of Renewable Energy, Ministry of Agriculture, China, Beijing 100083, China;

3. National Center for International Research of BioEnergy Science and Technology, Ministry of Science and Technology, China, Beijing 100083, China; 4. Hebei New Energy Technology Extension Station, Shijiazhuang, Hebei 050021, China; 5. Linyi Agricultural School, Linyi, Shandong 276600, China; 6. China Academy of Building Research, Beijing 100013, China; 7. Department of Energy, Environmental \& Chemical Engineering, Washington University in St. Louis, St. Louis, MO 63130, USA)

\begin{abstract}
Indoor air pollution is ranked the 5th in the Global Burden of Disease index of the World Health Organization (WHO). Almost half of the world's population depends on biomass fuels to meet their basic energy requirements for cooking, lighting and space heating. When fuel is badly combusted in poorly designed stoves, the fuel-stove combination results in high level of noxious emissions entering the home, accumulating to dangerous levels. In this study, a Chinese unvented top lit updraft (TLUD) biomass stove was operated with three different biomass pellets formed from corn stover, cotton stalk and peanut shells. The performance tests were conducted according to the latest standard from the Chinese Ministry of Agriculture. The calorific value, moisture level, volatile matter and elemental composition are reported for each. The thermal efficiencies of the stove were 15.3\%, 10.1\% and 14.4\%, respectively. The cooking powers were $2.68 \mathrm{~kW}, 1.61 \mathrm{~kW}$ and $1.57 \mathrm{~kW}$. The exhaust was collected using a hood and tunnel. The $\mathrm{CO}, \mathrm{NO}$ and $\mathrm{NO}_{\mathrm{X}}$ were drawn after passing $1.5 \mathrm{~m}$ along the tunnel and the Particulate Matter (PM) was sampled after $1.6 \mathrm{~m}$. The Emission Factors $(E F)$ for $\mathrm{CO}, \mathrm{NO}, \mathrm{NO}_{\mathrm{X}}$ and $\mathrm{PM}_{10}$ are reported on both a mass per unit energy delivered to the pot $\left(\mathrm{g} / \mathrm{MJ}_{\mathrm{NET}}\right)$ and a mass per mass of fuel basis $(\mathrm{g} / \mathrm{kg})$. The range for CO was 4.56-7.61 g/MJ $\mathrm{MJET}_{\mathrm{NET}}(11.25-$ $21.25 \mathrm{~g} / \mathrm{kg}$ ); NO was 0.75-1.23 g/MJ $\mathrm{MET}_{\mathrm{NET}}(2.09-3.04 \mathrm{~g} / \mathrm{kg})$; NOx was $1.13-1.90 \mathrm{~g} / \mathrm{MJ}_{\mathrm{NET}}$ (3.14-4.86 g/kg); PM 10 was 0.59$0.85 \mathrm{~g} / \mathrm{MJ}_{\mathrm{NET}}(1.67-2.09 \mathrm{~g} / \mathrm{kg})$. The range in these values was more significantly influenced by the fuel moisture content and the percentage of volatile matter than by variations in the elemental composition.
\end{abstract}

Keywords: indoor air pollution, biomass stove, pellets, thermal performance, emissions

DOI: $10.25165 /$ j.ijabe.20171004.2963

Citation: Zhang Z X, Sun Z F, Zhang Y H, Ding H Y, Zhou Y G, Zhang Y X, et al. Effects of biomass pellet composition on the thermal and emissions performances of a TLUD cooking stove. Int J Agric \& Biol Eng, 2017; 10(4): 189-197.

\section{Introduction}

Since prehistoric times, evidence that indoor air

Received date: 2016-11-04 Accepted date: 2017-03-20

Biographies: Zhang Zongxi, PhD candidate, major in emission examining of biofuel combustion, Email: jnzhangzongxi@163.com; Sun Zhenfeng, Senior Engineer, major in renewable energy and stoves promotion, Email: 76009713@qq.com; Zhang Yinghua, Master, major in vocational and technical education, Email: yszhangyinghua@163.com; Ding Hongyan, Master, major in biomass engineering, Email: dhybyrant@163.com; Zhang Yixiang, $\mathrm{PhD}$ candidate, major in biomass engineering, Email: yinhezhixing2005@163.com; Riaz Ahmad, PhD candidate, major pollution has stalked humans seeking a more comfortable life can be found in the streaked ceiling of their caves. Their shelters enclosed the fires that provided protection,

in gasifier stove design and performance test, Email: riaz.ch_a@ yahoo.com; Crispin Pemberton-Pigott, Senior Engineer, major in stove performance test, Email: crispinpigott@outlook.com; Dong Renjie, Professor, major in biomass engineering, Email: rjdong@cau. edu.cn.

*Corresponding author: Zhou Yuguang, PhD, Associate Professor, major in biomass engineering, China Agricultural University, No. 17 Qinghua Donglu, Haidian District, Beijing 100083, China. Tel: +86-10-62737858, Fax: +86-10-62737885, Email: zhouyg@cau.edu.cn. 
cooking, warmth and light. The unexpected predator that joined them was the simultaneous increase in exposure to smoke from the crackling fire ${ }^{[1]}$.

The utilization of solid fuels for cooking and heating was probably the largest source of indoor air pollution (IAP) globally ${ }^{[2]}$. More than a third of the global population and up to $90 \%$ of rural households, almost all in developing countries, currently cook with solid fuels such as animal dung, wood, agricultural residues and coal $^{[3,4]}$. These fuels are typically burned in an open fire or traditional cooking stove with poor combustion and low cooking efficiency. Therefore, substantial amounts of toxic pollutants are emitted and directly cause IAP $^{[4]}$. IAP increased the risk of acute lower respiratory infections and may cause lung cancer, asthma, low birth weight and other adverse birth outcomes ${ }^{[5-7]}$, neurodevelopment impairments ${ }^{[8]}$, cardiovascular and other inflammatory condition ${ }^{[9-11]}$, eye diseases such as cataract and blindness $^{[12,13]}$, and headaches ${ }^{[14]}$.

In recent years, because of the increasing price of oil and the global economic crisis, research into and the dissemination of improved biomass stoves has been conducted on global level ${ }^{[15]}$. More than 160 stove programmes have been carried out in different nations ${ }^{[16]}$. Among these programmes, the Chinese National Improved Stoves Programme is regarded as the largest stove promotion programme, which has disseminated about 129 million stoves from 1982 to 1992. This project was followed by a market-based approach covering $65 \%$ of the rural Chinese population at that time ${ }^{[17-19]}$. The government-supported Indian National Program disseminated more than 2.8 million stoves between 1983 and 2002 $2^{[20-22]}$. Charcoal and wood stoves such as the Jiko Bora and Okoa have been promoted by the Tanzania Traditional Energy Development Organization since the $1980 s^{[23]}$. In rural Ethiopia some improved stoves were promoted, and Beyene et al. ${ }^{[24]}$ did some research on how often people use their improved stoves. About 500000 certified improved chimney stoves were adopted by $2009^{[25]}$. In Peru, 300000 improved stoves were built by the end of $2011^{[26]}$. According to summarize reported dates, all these biomass stove dissemination programmes have together promoted at least 179 million improved stoves, included 129 million in China, 13 million in the other countries of East Asia, 22 million in South Asia, 7 million in Sub-Saharan Africa and 8 million in Latin America and the Caribbean ${ }^{[27-31]}$.

Biomass has been widely used for cooking and heating purposes in China for thousands of years. However, IAP caused by burning firewood and agricultural residues remains a major problem associated with adverse health impacts ${ }^{[32]}$.

In this study, a typical Chinese biomass stove without a chimney is tested with three different biomass pellet fuels to see what influence the fuel composition has on emissions. The pellets were made from either corn stover, cotton stalk or peanut shells. The thermal efficiency and cooking power were reported and compared with the Ministry of Agriculture's current performance Standard. Flue gas was collected by a hood and samples drawn into test instruments. The particulate matter (PM) was sampled from the flue at a point $1.6 \mathrm{~m}$ from the flue entrance. Gaseous emissions measured included $\mathrm{CO}, \mathrm{NO}$ and $\mathrm{NO}_{\mathrm{X}}$. $\mathrm{PM}$ was measured for total mass and size distribution. The principal aim of the study was to investigate the influence of fuel type and moisture content on the thermal and emissions performance of a popular Chinese cooking stove.

\section{Materials and methods}

\subsection{Instruments}

A thermometer having the division value of $0.2^{\circ} \mathrm{C}$ was used to measure water temperature in the range of $0^{\circ} \mathrm{C}-100^{\circ} \mathrm{C}$. A gas analyzer (MRU MGA5/Vario Plus, Germany) was used to measure $\mathrm{CO}, \mathrm{CO}_{2}, \mathrm{O}_{2}, \mathrm{NO}, \mathrm{NO}_{2}$, $\mathrm{NO}_{\mathrm{X}}, \mathrm{CH}_{4}$ and $\mathrm{C}_{\mathrm{X}} \mathrm{H}_{\mathrm{Y}}$. Table 1 shows the detailed parameters of the gas analyzer. DP-Calc Micromanometer (Model 5815, TSI, Shoreview, MN, USA) was used to measure the velocity of the flue gas with the range of $0.27-78.7 \mathrm{~m} / \mathrm{s}$ and a precision of $0.1 \mathrm{~m} / \mathrm{s}$.

Nine stage cascade impactor (FA-3, Liaoyang Applied Technology Research Institute, China) was used to characterize the PM emissions. This instrument divides the sample into nine aerodynamic sizes. Table 2 
shows the details of the particular matter size distribution for each stage. A high precision digital mass balance (MS105DU, Mettler Toledo, Switzerland, $0.01 \mathrm{mg}$ ) was used to determine the mass of PM on the filters.

\section{Table 1 Detailed information of MRU VARIO PLUS}

\begin{tabular}{cccc}
\hline Content & Type of sensors & Measuring range & Accuracy \\
\hline $\mathrm{NO}$ & Electrochemical sensor & $0-5000 \mathrm{ppm}$ & $\pm 5 \% \mathrm{MV}$ \\
$\mathrm{NO}_{2}$ & Electrochemical sensor & $0-1000 \mathrm{ppm}$ & $\pm 5 \% \mathrm{MV}$ \\
$\mathrm{NO}_{\mathrm{X}}$ & $\mathrm{NO}+\mathrm{NO}_{2}=\mathrm{NOx}$ & $0-6000 \mathrm{ppm}$ & $/$ \\
$\mathrm{CO}_{2}$ & NDIR sensor & $0-20.0 \%$ & $\pm 2 \% \mathrm{FS}$ \\
$\mathrm{CO}$ & NDIR sensor & $0-30000 \mathrm{ppm}$ & $\pm 2 \% \mathrm{FS}$ \\
$\mathrm{O}_{2}$ & Electrochemical sensor & $0-21.0 \%$ & $\pm 2 \% \mathrm{FS}$ \\
$\mathrm{CH}_{4}$ & $\mathrm{NDIR}$ & $0-5000 \mathrm{ppm}$ & $\pm 2 \% \mathrm{FS}$ \\
$\mathrm{C}_{\mathrm{X}} \mathrm{H}_{\mathrm{Y}}$ & $\mathrm{NDIR}\left(\mathrm{C}_{3} \mathrm{H}_{6}\right)$ & $0-3.0 \%$ & $\pm 2 \% \mathrm{FS}$ \\
\hline
\end{tabular}

Note: NDIR = Non-dispersive infra-red; MV = Measured value; FS = Full scale reading.

Table 2 PM size distribution sampled by nine-stage cascade impactor

\begin{tabular}{cc}
\hline Stages & Size $/ \mu \mathrm{m}$ \\
\hline 0 & $9.0-10$ \\
1 & $5.8-9.0$ \\
2 & $4.7-5.8$ \\
3 & $3.3-4.7$ \\
4 & $2.1-3.3$ \\
5 & $1.1-2.1$ \\
6 & $0.65-1.1$ \\
7 & $0.43-0.65$ \\
8 & $<0.43$ \\
\hline
\end{tabular}

\subsection{Fuels}

A typical Chinese household biomass stove without a chimney was selected and fueled with different kinds of biomass pellet fuels. Figure 1 shows the stove used and the stove structure is shown in Figure 2.

Biomass fuel pellets made of corn stover, cotton stalk and peanut shells had a diameter of $8 \mathrm{~mm}$ and a length of $30 \mathrm{~mm}$. A gelled alcohol brick (HS50-M, China) was used for ignition, the calorific value of which is $14000 \mathrm{~kJ} / \mathrm{kg}$.

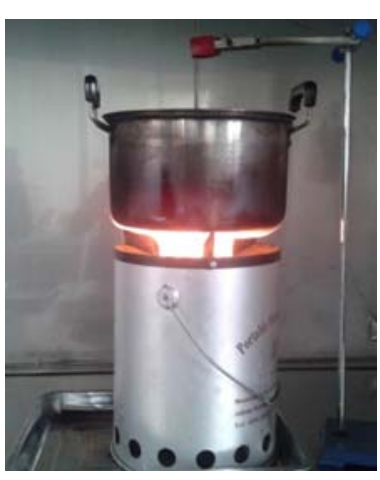

Figure 1 Photo of the tested stove

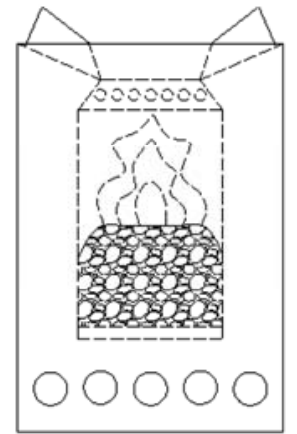

Figure 2 Illustration of the tested stove structure

The mass of PM was determined using a high precision digital mass balance. Quartz fiber filters were used to collect the PM in each of the 9 stages. New filters were first baked in a muffle furnace at $450^{\circ} \mathrm{C}$ for $6 \mathrm{~h}$ to remove any organic matter. The filters were then equilibrated in a constant-temperature $\left(30^{\circ} \mathrm{C}\right)$ and constant-humidity (50\% relative humidity) chamber for $24 \mathrm{~h}$ and weighed before and after sampling. The difference between the initial mass and final mass of each equilibrated sample is regarded as the mass of PM collected on that stage.

\subsection{Stove testing system}

The experimental apparatus used was developed by the Bioenergy and Environmental Science \& Technology Laboratory, College of Engineering, China Agricultural University, and the stove test system is shown in Figure 3. The exhaust gas was collected by a stainless steel hood with the size of $1.2 \mathrm{~m} \times 1.2 \mathrm{~m}$. The required flow rate feeding the aerosol impactor was $28.3 \mathrm{~L} / \mathrm{min}$, driven by a constant flow air sample pump. A variable speed fan attached to the end of the tunnel was used to evacuate the hood and control the level of dilution of the exhaust. The gas sampling point was drawn $1.5 \mathrm{~m}$ after the tunnel entrance and PM was sampled $0.1 \mathrm{~m}$ after the gas sampling point.

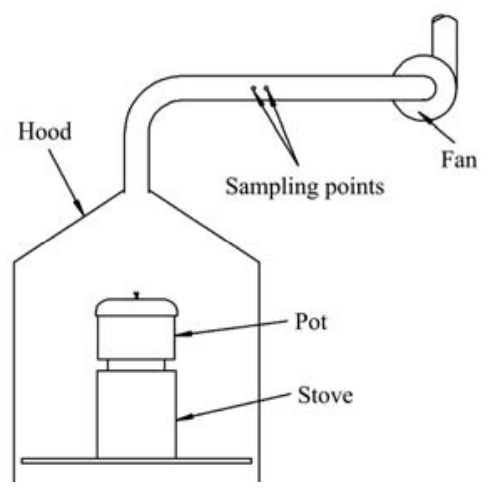

Figure 3 Exhaust sampling system used in this study 


\subsection{Methods}

A typical Chinese biomass stove without a chimney was tested with different biomass pellet fuels in accordance with the current version of standards that issued by Chinese Ministry of Agriculture: General Technical Specification of Domestic Biofuel Cooking Stove (NY/T 2369-2013) ${ }^{[33]}$ and Test Performance Method of Domestic Biofuel Cooking Stove (NY/T $2370-2013)^{[34]}$. For each test $1.5 \mathrm{~kg}$ of fuel was loaded into the stove and $5 \mathrm{~L}$ of water at room temperature was loaded into the pot. All the tests were done at the Biomass Stove Testing Center belonging to the Bioenergy and Environment Science \& Technology Laboratory, College of Engineering, China Agricultural University. The calorific value, moisture content, volatile matter content and elemental composition were analyzed by North China Electric Power University according to the method described in three existing standards Densified Biofuel-test Methods Part 1: General Principle (NY/T 1881.1-2010), Proximate Analysis of Solid Biofuels (GB/T 28731-2012), and Determination of Carbon and Hydrogen in Solid Biofuel (GB/T 28734-2012).

\subsection{Calculations}

\subsubsection{Calculation of cooking efficiency}

Cooking efficiency was calculated using the following thermal efficiency formula (Equation (1)) from the standard document Test Performance Method of Domestic Biofuel Cooking Stove (NY/T 2370-2013) ${ }^{[34]}$ :

$$
\eta=\frac{4.18 \times\left[G_{1} \times\left(t_{2}-t_{1}\right)\right]+\left(G_{1}-G_{2}\right) \times r}{B C+B_{1} C_{1}}
$$

where, $\eta=$ cooking power, $\mathrm{kW} ; G_{1}=$ initial water mass, $\mathrm{kg} ; G_{2}=$ remaining water mass, $\mathrm{kg} ; t_{1}=$ initial water temperature, ${ }^{\circ} \mathrm{C} ; t_{2}=$ water temperature at boiling point, ${ }^{\circ} \mathrm{C} ; \quad r=$ average latent heat of vaporization at the evaporation temperature, $2257 \mathrm{~kJ} / \mathrm{kg} ; 4.18$ = water specific heat, $\mathrm{kJ} /\left(\mathrm{kg} \cdot{ }^{\circ} \mathrm{C}\right) ; B=$ Fuel mass loaded, kg; $C=$ Lower Heating Value as Received $\left(\mathrm{LHV}_{\mathrm{AR}}\right)$ of the fuel, $\mathrm{kJ} / \mathrm{kg} ; B_{1}=$ mass of ignition fuel, kg; $C_{1}=$ As Received $\mathrm{LHV}_{\mathrm{AR}}$ of the ignition fuel, $\mathrm{kJ} / \mathrm{kg}$.

\subsubsection{Calculation of cooking power}

Cooking power was calculated by the following formula (Equation (2)) according to Test performance method of domestic biofuel cooking stove (NY/T $2370-2013)^{[34]}$.

$$
P=\frac{4.18 \times\left[G_{1} \times\left(t_{2}-t_{1}\right)\right]+\left(G_{1}-G_{2}\right) \times r}{T_{2}-T_{1}}
$$

where, $P=$ cooking power, $\mathrm{kW} ; T_{1}=$ ignition time, h: min [seconds]; $T_{2}=$ boiling time, h: $\min$ [seconds].

\section{Results and discussion}

\subsection{Fuel compositional analysis}

The calorific value, moisture content and volatile matter content of each fuel was tested and the elemental composition determined. The results are presented in Table 3. The moisture content of peanut shell pellets was the highest of the three and it reduced the combustion and emissions performance. However, because the heating value of peanut shell pellets is high, it releases more energy per unit mass. Because the volatile matter content of these pellets is low, it burns at a lower rate. The nitrogen content of corn stover pellets was ranked highest so it should create the highest $\mathrm{NO}_{\mathrm{X}}$ emission. However, $\mathrm{NO}_{\mathrm{X}}$ formation is dependent on the combustion temperature and the ranking is not guaranteed ${ }^{[35]}$.

Table 3 Industrial analysis and elemental analysis of fuel

\begin{tabular}{cccccccc}
\hline Content & $M_{a d} / \%$ & $A_{a d} / \%$ & $V_{a d} / \%$ & $F C_{a d} / \%$ & $C_{a d} / \%$ & $H_{a d} / \%$ & $N_{a d} / \%$ \\
\hline Cotton stalk & 11.1 & 1.5 & 73.06 & 11.5 & 51.6 & 6.0 \\
Peanut shell & 14.3 & 1.6 & 68.68 & 15.42 & 54.9 & 6.60 \\
Corn stover & 8.5 & 5.93 & 67.82 & 17.75 & 40.45 & 1.933 & 5.5 \\
\hline
\end{tabular}

Note: $M_{a d}$ means moisture content; $A_{\text {ad }}$ means ash content; $V_{\text {ad }}$ means volatile matter content, $F C_{\text {ad }}$ means fixed carbon content; $C_{\text {ad }}$ means carbon content; $H_{\text {ad }}$ means hydrogen content; $N_{\text {ad }}$ means nitrogen content; $Q_{\text {net, ar }}$ means received calorific value.

\subsection{Thermal performance}

\subsubsection{Water temperature changing}

As shown in Figure 4, at the beginning of the test, the water temperature in the pot increased slowly. This stems from the fact that fuel with a high moisture content often requires additional energy to vaporize the fuel moisture resulting in a low net energy release rate. During this fuel-drying phase the emissions can be high $^{[36,37]}$. Pelleted biomass has many pores which will readily absorb moisture. The evaporation of this 
moisture absorbs the energy released during combustion.

The loss of energy needed to dry the fuel reduces the temperature in the combustion chamber. In the beginning the amount of heat available to warm the water is limited. The fuel with high moisture content, such as wood with the moisture content above 60\% cannot maintain proper combustion. At 60\% moisture the chamber temperature is below that required to sustain combustion $^{[38,39]}$.

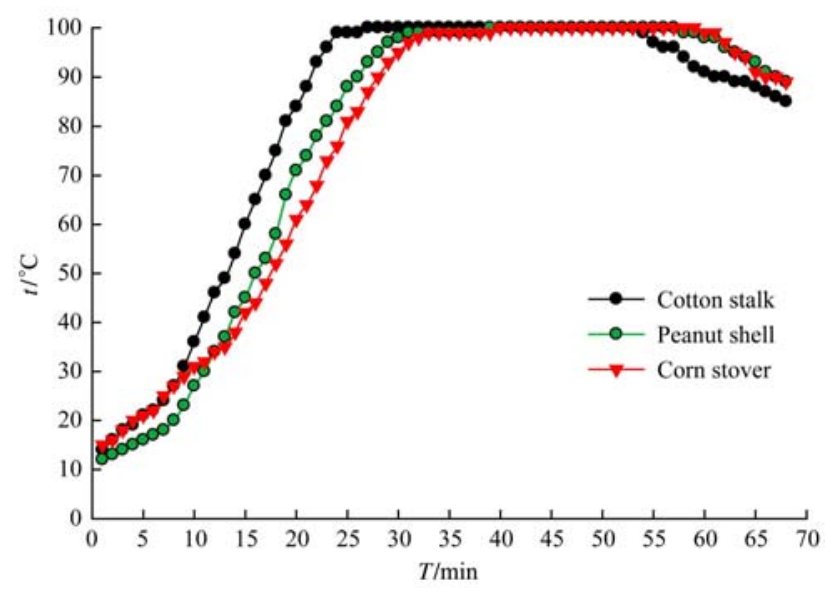

Figure 4 Temperature rise of water in the pot as the tested stove burning different biomass pellets

Peanut shell pellets delivered the lowest water heating rate because the moisture content was the highest of the three tested biomass pellets fuels.

The density of corn stover pellets was the highest. The cotton stalk pellet density was similar to that of the peanut shells. The fuel density exerted an influence on the fuel combustion rate. The volatile matter content of cotton stalk pellets was highest followed by peanut shells and then corn stover. Corn stover pellets had the worst combustion performance in this stove. The water heating performance using cotton stalk pellets was best followed by the peanut shell pellets. The corn stover cost the longest time to boiling certain mass of water.

\subsubsection{Cooking efficiency}

The cooking efficiency results are presented in Figure 5. The highest was obtained using cotton stalk pellets followed corn stover and then peanut shells. It is assumed that any increase in the moisture content reduces the combustion temperature and efficiency ${ }^{[25,40,41]}$. Because, as shown in Table 3, the moisture content of peanut shell pellets was the highest, it is expected that the energy would lose when drying it reduced the cooking efficiency the most. Because the moisture and ash content of corn stover was higher than for cotton stalks, the cooking efficiency of the former was lower.

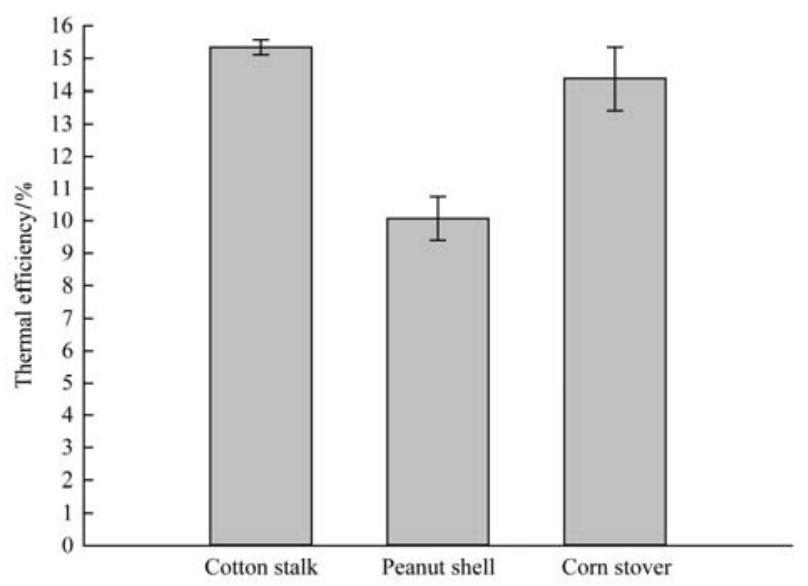

Figure 5 Cooking efficiency of the tested stove burning different biomass pellets

\subsubsection{Cooking power}

The cooking power is presented in Figure 6. The highest cooking power was obtained by burning cotton stalk pellets, followed peanut shells and finally corn stover. The combustion performance of corn stover was the worst, so it took the longest time for the fuel burn out. As shown in Table 3, the moisture content of peanut shell pellets did result in a reduction of cooking power.

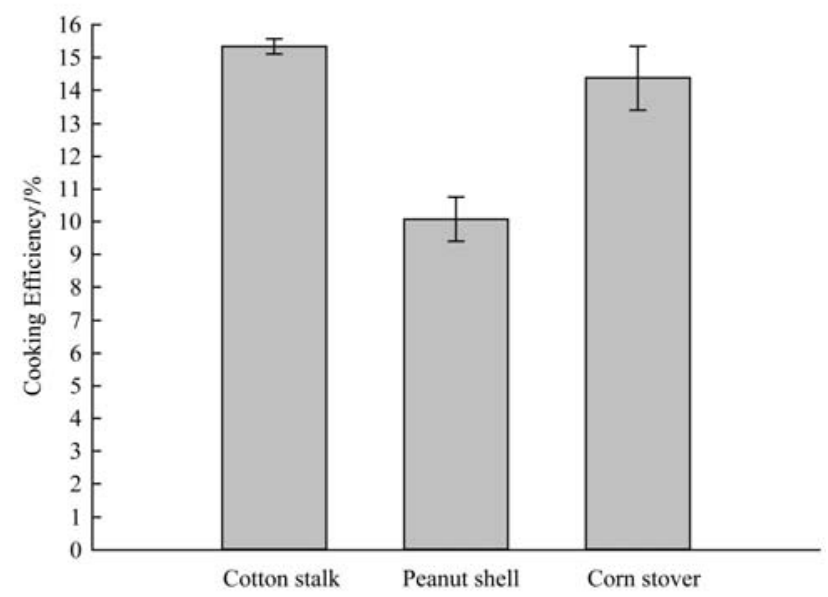

Figure 6 Cooking power of the tested stove burning different kinds of biomass pellets

\subsection{Emission performance}

\subsubsection{Gas emissions}

The gas emissions included $\mathrm{CO}, \mathrm{CO}_{2}, \mathrm{O}_{2}, \mathrm{NO}, \mathrm{NO}_{2}$, $\mathrm{NO}_{\mathrm{X}}, \mathrm{CH}_{4}$ and $\mathrm{C}_{\mathrm{X}} \mathrm{H}_{\mathrm{Y}}$. During the tests $\mathrm{CO}, \mathrm{NO}$ and $\mathrm{NO}_{\mathrm{X}}$ were monitored continuously. The masses of CO, $\mathrm{NO}, \mathrm{NO}_{\mathrm{X}}$, and their $E F$ are presented in Table 4.

It can be seen from Table 4 that the $\mathrm{CO}$ emitted when burning cotton stalk pellets was the highest. During 
biomass combustion, a certain concentration of volatiles are on the surface of the fuel and the volatiles should be exposed to oxygen at a suitable temperature ${ }^{[42]}$. This might be the reason why the stove showed the best combustion efficiency when burning cotton stalk pellets. If the fuel burns too quickly it can result in incomplete combustion because of insufficient oxygen ${ }^{[36,37]}$. A similar effect can be seen when the fuel moisture content is high as was the case with the cotton stalk pellets. Huangfu et al. ${ }^{[42]}$ reported on some experiments using a biomass-fueled semi-gasifier stove with a structure similar to that used by the authors. They investigated how the moisture content of the fuel affected the thermal and emissions performance when burning wood pellets. The range of $E F_{\mathrm{CO}}$ was from $2.7 \mathrm{~g} / \mathrm{MJ}_{\mathrm{NET}}$ to $4.4 \mathrm{~g} / \mathrm{MJ}_{\mathrm{NET}}$ with a moisture content which varied from 5.9\% to $22.1 \%{ }^{[43]}$. The moisture content of cotton stalk pellets used in our study was $11.1 \%$ and the $E F_{\mathrm{CO}}$ was $7.61 \pm 3.11$ $\mathrm{g} / \mathrm{MJ}_{\mathrm{NET}}$, almost double the figure given by Huangfu et al. $\left(E F_{\mathrm{CO}} 3.5 \mathrm{~g} / \mathrm{MJ}_{\mathrm{NET}} \text { with moisture content of } 9.4 \%\right)^{[42]}$. There may be several reasons for the difference: the moisture content, operator behaviour or the raw materials.

Table 4 Results of $\mathrm{CO}$, NO and $\mathrm{NO}_{\mathrm{X}}$ emissions and $E F$

\begin{tabular}{|c|c|c|c|c|c|c|c|c|c|}
\hline \multirow{2}{*}{ Fuel type } & \multicolumn{3}{|c|}{$\mathrm{CO}$} & \multicolumn{3}{|c|}{ NO } & \multicolumn{3}{|c|}{$\mathrm{NO}_{\mathrm{X}}$} \\
\hline & Mean/g & $E F / \mathrm{g} \cdot \mathrm{MJ}_{\mathrm{NET}}^{-1}$ & $E F / \mathrm{g} \mathrm{kg}^{-1}$ & Mean/g & $E F / \mathrm{g} \cdot \mathrm{MJ}_{\mathrm{NET}}{ }^{-1}$ & $E F / \mathrm{g} \cdot \mathrm{kg}^{-1}$ & Mean/g & $E F / \mathrm{g} \cdot \mathrm{MJ}_{\mathrm{NET}}{ }^{-1}$ & $E F / \mathrm{g} \cdot \mathrm{kg}^{-1}$ \\
\hline Cotton stalk & $31.87 \pm 13.04$ & $7.61 \pm 3.11$ & $21.25 \pm 8.69$ & $3.13 \pm 0.23$ & $0.75 \pm 0.05$ & $2.09 \pm 0.15$ & $4.72 \pm 0.32$ & $1.13 \pm 0.08$ & $3.14 \pm 0.21$ \\
\hline Peanut shells & $19.03 \pm 0.34$ & $5.79 \pm 0.10$ & $12.69 \pm 0.23$ & $2.57 \pm 0.24$ & $0.78 \pm 0.07$ & $1.72 \pm 0.16$ & $3.92 \pm 0.46$ & $1.19 \pm 0.14$ & $2.62 \pm 0.31$ \\
\hline Corn stover & $16.88 \pm 5.61$ & $4.56 \pm 1.51$ & $11.25 \pm 3.74$ & $4.56 \pm 0.73$ & $1.23 \pm 0.20$ & $3.04 \pm 0.48$ & $7.03 \pm 1.18$ & $1.90 \pm 0.32$ & $4.68 \pm 0.79$ \\
\hline
\end{tabular}

Note: $E F$ with unit of g/MJ $\mathrm{MJ}_{\mathrm{NET}}$ means how much emission produced when one MJ useful energy is delivered to the pot. $E F$ with the unit of g/kg means how much emission produced when one kg fuel burned.

Nitrogen oxides $\left(\mathrm{NO}_{\mathrm{X}}\right)$ are produced during combustion and consisted of both $\mathrm{NO}$ and $\mathrm{NO}_{2}$ (NO accounted for about $95 \%$ of $\mathrm{NO}_{\mathrm{X}}$, and the rest $5 \%$ is $\left.\mathrm{NO}_{2}\right)^{[32]}$. The generation of $\mathrm{NO}_{\mathrm{X}}$ was closely connected with the combustion temperature and its availability in the fuel. There are three types of $\mathrm{NO}_{\mathrm{X}}$ : fuel-type $\mathrm{NO}_{\mathrm{X}}$, thermal-type $\mathrm{NO}_{\mathrm{X}}$ and rapid-type $\mathrm{NO}_{\mathrm{X}}$. Fuel-type $\mathrm{NO}_{\mathrm{X}}$ is produced by the decomposition of fuel nitrogen at high temperature and accounts for $60 \%-80 \%$ of $\mathrm{NO}_{\mathrm{X}}{ }^{[44]}$. The $\mathrm{NO}$ and $\mathrm{NO}_{\mathrm{X}}$ emissions from corn stover pellets were the highest because it has the highest fuel nitrogen content.

\subsubsection{PM size distribution and PM emission factors}

PM size distribution is shown in Figure 7. When the stove burned corn stover pellets, PM with an aerodynamic diameter less than $5.8 \mu \mathrm{m}$ was highest, accounting for $94.8 \%$ of the total PM emission, followed by cotton stalk pellets (92.1\%) and peanut shell pellets (89.0\%). For cotton stalk pellets, the mass of $\mathrm{PM}_{0.7}$ accounted for $44.5 \%$, higher than peanut shell pellets (42.2\%) and corn stover pellets (40.7\%). In this study, the stove produced very little $\mathrm{PM}_{5.9-10}$ whatever the fuel. The PM masses for each stage are presented in Table 5.

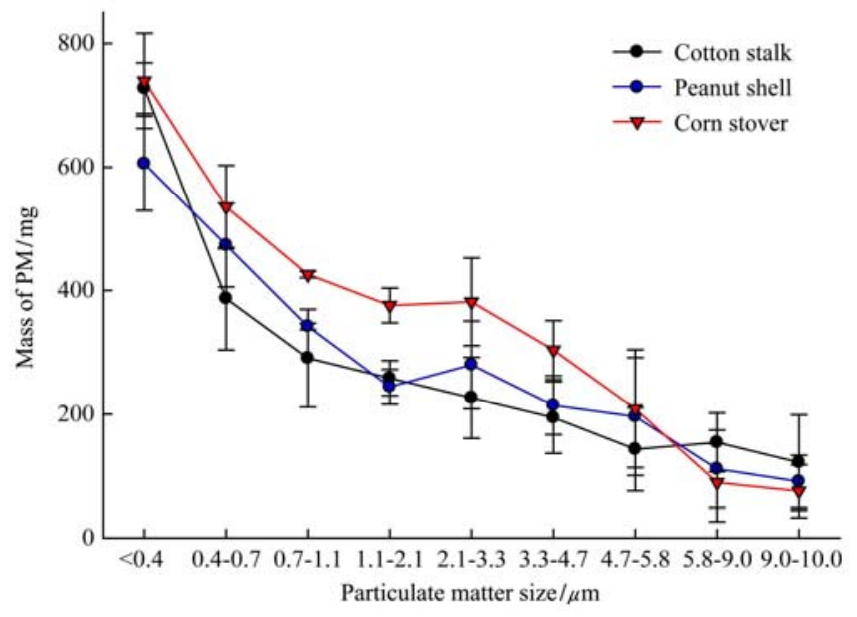

Figure 7 PM size distribution of the tested stove burning the three kinds of tested biomass pellets

Table 5 PM mass ratio for each particle size range

\begin{tabular}{|c|c|c|c|c|c|c|c|c|c|}
\hline \multirow{2}{*}{ Fuel type } & \multicolumn{9}{|c|}{ particle size $/ \mu \mathrm{m}$} \\
\hline & $<0.4$ & $0.43-0.65$ & $0.65-1.1$ & $1.1-2.1 \mu \mathrm{m}$ & 2.1-3.3 & $3.3-4.7$ & $4.7-5.8$ & $5.8-9.0$ & $9.0-10$ \\
\hline Cotton stalk & 29.06 & 15.45 & 11.61 & 10.32 & 9.05 & 7.77 & 5.72 & 6.16 & 4.86 \\
\hline Peanut shell & 23.68 & 18.50 & 13.37 & 9.56 & 10.94 & 8.38 & 7.67 & 4.35 & 3.55 \\
\hline Corn stover & 23.59 & 17.07 & 13.59 & 11.99 & 12.17 & 9.69 & 6.66 & 2.84 & 2.40 \\
\hline
\end{tabular}


The mass of $\mathrm{PM}_{10}$ and $\mathrm{PM}_{2.1}$ is presented in Table 6. The highest $\mathrm{PM}_{10}$ mass was produced when burning corn stover pellets, follow by peanut shell pellets, then cotton stalk pellets. The $\mathrm{PM}_{10}$ masses were $(3.14 \pm 0.10) \mathrm{g}$, $(2.56 \pm 0.25) \mathrm{g}$ and $(2.50 \pm 0.16) \mathrm{g}$, respectively. The masses of $\mathrm{PM}_{2.1}$ were $(2.08 \pm 0.09) \mathrm{g},(1.67 \pm 0.05) \mathrm{g}$ and (1.66 \pm 0.18$)$ g, respectively. $\mathrm{PM}_{2.1}$ accounts for $66.23 \%$, $65.11 \%$ and $66.44 \%$, of their respective totals. These results are significantly different from those found by Shen et al. ${ }^{[45]}$ which reported that $79.4 \%$ of the total PM was $\mathrm{PM}_{2.5}$ for wood combustion and over $81 \%$ of the total PM from crop residues ${ }^{[46]}$. It is believed the source of the difference was that of using a $4.5 \mathrm{~m}^{3}$ mixing chamber with a fan in which most of the large particulate matter settled and small particles coagulated before measurement ${ }^{[45]}$.

Table 6 EF for various biomass pellets

\begin{tabular}{cccccc}
\hline Fuel type & $\begin{array}{c}\text { Mean total } \\
\mathrm{PM} / \mathrm{g}\end{array}$ & $\begin{array}{c}\text { Standard } \\
\text { deviation }\end{array}$ & $\begin{array}{c}\mathrm{PM}_{2.1} / \\
\mathrm{g}\end{array}$ & $\begin{array}{c}E F / \\
\mathrm{g} \cdot \mathrm{MJ}_{\mathrm{NET}}^{-1}\end{array}$ & $\begin{array}{c}E F / \\
\mathrm{g} \cdot \mathrm{kg}^{-1}\end{array}$ \\
\hline Cotton stalk & 2.50 & 0.16 & 0.94 & 0.59 & 1.67 \\
Peanut shell & 2.56 & 0.25 & 1.06 & 0.78 & 1.71 \\
Corn stover & 3.14 & 0.10 & 1.34 & 0.85 & 2.09 \\
\hline
\end{tabular}

When burning cotton stalk pellets, peanut shell pellets and corn stover pellets, the $E F_{\mathrm{PM}}$ per $\mathrm{MJ}_{\mathrm{NET}}$ and (per kg) were, respectively, $(0.59 \pm 0.04) \mathrm{g} / \mathrm{MJ}_{\mathrm{NET}},(1.67 \pm 0.11) \mathrm{g} / \mathrm{kg}$, $(0.78 \pm 0.08) \mathrm{g} / \mathrm{MJ}_{\mathrm{NET}},(1.71 \pm 0.17) \mathrm{g} / \mathrm{kg}$ and $(0.85 \pm 0.03)$ $\mathrm{g} / \mathrm{MJ}_{\mathrm{NET}},(2.09 \pm 0.06) \mathrm{g} / \mathrm{kg}$. These results were similar to the results of Shen et al.: for crop residues, the results obtained were $E F_{\mathrm{PM}}(1.38 \pm 0.70) \mathrm{g} / \mathrm{kg}^{[46]}$ and $(2.2 \pm 1.2)$ $\mathrm{g} / \mathrm{kg}^{[45]}$ for wood. This is significantly different from the results of Huangfu et al. ${ }^{[42]}: E F_{\mathrm{PM} 2.5}$ range 0.19 $\mathrm{mg} / \mathrm{MJ}_{\mathrm{NET}}$ to $0.58 \mathrm{mg} / \mathrm{MJ}_{\mathrm{NET}}$ for fuel moisture $5.9 \%$ to $22.1 \%$. The results are also significantly different from the results of Jetter et al. ${ }^{[47]}: E F_{\mathrm{PM} 2.5}$ was $0.7-1.4 \mathrm{mg} / \mathrm{MJ}_{\mathrm{NET}}$ for a base-case stove and $0.07 \mathrm{mg} / \mathrm{MJ}_{\mathrm{NET}}$ for a technologically advanced one. This mismatch may have been caused by James having done the tests according to Water Boiling Test (WBT) protocol.

The WBT protocol, Version 4, specifies a different stove operating sequence. The $E F_{\mathrm{PM}}$ is dramatically different because of the combined effects of the very different test sequence and calculation method. The test sequence changes the combustion efficiency and combustion conditions. With its different fire management sequence, the combustion temperature, oxygen supply, mixing states and the differences in fuel evolution result in an $E F_{\mathrm{PM}}$ that is strongly at variance with the test sequence employed in this work ${ }^{[40,42,48,49]}$.

\section{Conclusions and recommendations}

Corn stover, cotton stalk and peanut shell pellets were combusted in a popular TLUD Chinese biomass stove. The highest thermal efficiency was obtained when burning cotton stalk pellets ( $15.3 \% \pm 0.2 \%)$, followed corn stover pellets $(14.4 \% \pm 0.7 \%)$ and finally, peanut shell pellets $(10.1 \% \pm 1.0 \%)$. The stove delivered the highest cooking power when burning cotton stalk pellets, followed by peanut shell pellets, then corn stover pellets. The highest mass of PM was emitted by corn stover pellets follow by peanut shell pellets, finally cotton stalk pellets. The combustion of cotton stalk pellets produced much more fine particulate matter.

It is concluded that the thermal efficiency, cooking power, gaseous emissions, the particulate matter size distribution and Emission factors differed significantly for this stove, differences caused by the match or mis-match between the stove architecture and fuel properties such as moisture content, volatile matter fraction and elemental composition. Further study should be done with different stoves testing a diverse range of fuels try discover which fuel attributes and which stove architectures combine to deliver superior performance.

\section{Acknowledgements}

This work carried out at the Key Laboratory of Clean Production and Utilization of Renewable Energy, Ministry of Agriculture, P. R. China; and National Center for International Research of BioEnergy Science and Technology, Ministry of Science and Technology, P. R. China. This study was supported by the joint projects of China and South Africa "Development of Scientifically Robust and Culturally Appropriate Metrics and Protocols for Evaluating Clean (Combustion) Cookstoves” (Grant No. 201404810710566); the grant from the World Bank Group for "Support Clean Stove Measure under Hebei Pollution Prevention and Control”; support from Rural 
Energy and Environmental Agency, Ministry of Agriculture, China; South-South Sustainable Stove Group; and Beijing Municipal Key Discipline of Biomass Engineering.

\section{[References]}

[1] Albalak R. Cultural practices and exposure to particles pollution from indoor biomass cooking: effects on respiratory health and nutritional status among the Aymara Indians of the Bolivian Highlands. University of Michigan, MI, USA, 1997.

[2] Smith K R, Mehta S, Maeusezahl-Feuz M. Indoor air pollution from household use of solid fuels. Comparative Quantification of Health Risks, 2004; 18: 1435-1492.

[3] World Resources Institute, United Nations Environment Programme, United Nations Development Programme, World Bank. 1998-99 world resources: a guide to the global environment. Oxford University Press, Oxford, UK, 1998.

[4] Bruce N, Perez-Padilla R, Albalak R. Indoor air pollution in developing countries: a major environmental and public health challenge. Bulletin of the World Health Organisation, 2000; 78(9): 1078-1092.

[5] Siddiqui A R, Gold E B, Yang X W, Lee K, Brown K H, Bhutta Z A. Prenatal exposure to wood fuel smoke and low birth weight. Environmental Health Perspectives, 2008; 116(4): 543-549.

[6] Po J Y T, Fitzgerald J M, Carlsten C. Respiratory disease associated with solid biomass fuel exposure in rural women and children: systematic review and meta-analysis. Thorax, 2011; 66(3): 232-239.

[7] Pope D P, Mishra V, Thompson L, Siddiqui A R, Rehfuess E A, Weber M, et al. Risk of low birth weight and stillbirth associated with indoor air pollution from solid fuel use in developing countries. Epidemiologic Reviews, 2010; 32(1): 70-81.

[8] Dix-Cooper L, Eskenazi B, Romero C, Balmes J, Smith K R. Neurodevelopmental performance among school age children in rural Guatemala is associated with prenatal and postnatal exposure to carbon monoxide, a marker for exposure to woodsmoke. NeuroToxicology, 2012; 33(2): 246-254.

[9] Truong D L, Jaumard B. Indoor air pollution and blood pressure in adult women living in rural China. Environmental Health Perspectives, 2011; 119(10): 1390-1395.

[10] Clark M L, Reynolds S J, Burch J B, Conway S, Bachand A M, Peel J L. Indoor air pollution, cookstove quality, and housing characteristics in two Honduran communities. Environmental Research, 2010; 110(1): 12-18.

[11] John M C, Smith K R, Peter S, Anaité D, Arana B, Schwartz J. Intervention to lower household wood smoke exposure in Guatemala reduces ST-segment depression on electrocardiograms. Environmental Health Perspectives, 2011; 119(11): 1562-1568.

[12] Saha A, Kulkarni P K, Shah A, Pate M, Saiyed H N. Ocular morbidity and fuel use: an experience from India. Occupational and Environmental Medicine, 2005; 62(1): 66-69.

[13] Smith K R, Mehta S. The burden of disease from indoor air pollution in developing countries: comparison of estimates. International Journal of Hygiene and Environmental Health, 2003; 206(4-5): 279-289.

[14] Díaz E, Smith-Sivertsen T, Pope D, Tlie R T, Díaz A, McCracken J, et al. Eye discomfort, headache and back pain among Mayan Guatemalan women taking part in a randomised stove intervention trial. Journal of Epidemiology and Community Health, 2007; 61(1): 74-79.

[15] Kshirsagar M P, Kalamkar V R. A comprehensive review on biomass cookstoves and a systematic approach for modern cookstove design. Renewable and Sustainable Energy Reviews, 2014; 30: 580-603.

[16] Ruiz-Mercado I, Masera O, Zamora H, Smith K R. Adoption and sustained use of improved cookstoves. Energy Policy, 2011; 39(12): 7557-7566.

[17] Bailis R, Cowan A, Berrueta V, Berrueta O. Arresting the killer in the kitchen: The promises and pitfalls of commercializing improved cookstoves. World Development, 2009; 37(10): 1694-1705.

[18] Edwards R D, Liu Y, He G, Yin Z, Sinton J, Peabody J, et al. Household CO and PM measured as part of a review of China's National Improved Stove Program. Indoor Air, 2007; 17(3): 189-203.

[19] Zhang J J, Smith K R. Household air pollution from coal and biomass fuels in China: measurements, health impacts, and interventions. Environmental Health Perspectives, 2007; 115(6): 848-855.

[20] Kishore V V N, Ramana P V. Improved cookstoves in rural India: how improved are they? A critique of the perceived benefits from the National Programme on Improved Chulhas (NPIC). Energy, 2002; 27(1): 47-63.

[21] Philippone L E. What's cooking?: a mixed methods study of health perceptions and use of improved cookstoves in rural India. Dissertations and Thesis: Gradworks, Duke University, Durham, NC, USA, 2015.

[22] Morrison L. Fueling Demand: The effect of rebates on household purchase of improved cookstoves in rural India. Household Air Pollution Improved Cookstoves Subsidies Rebates India, 2014.

[23] Sawe E N. Wood fuels stoves development and promotion in Tanzania: Some selected experiences. Presentation to the European Biomass/COMPETE Workshop on Bioenergy for Rural Development in Africa and Asia, 30 Jun 2009. Available from: http://www.compete-bioafrica.net/events/ events2/hamburg/Session\%202/S2-5-COMPETE-REImpactHamburg-Sawe-090630.pdf. Accessed on [2016-08-05] 
[24] Beyene A D, Bluffstone R, Gebreegziabher Z, Martinsson P, Mekonnen A, Vieider F. The improved biomass stove saves wood, but how often do people use it? Evidence from a randomized treatment trial in Ethiopia. Social Science Electronic Publishing, 2015.

[25] Bodereau P N. Peruvian highlands, fume-free. Guest Editorial. Science, 2011; 334: 157-157.

[26] Johnson M A, PilcobV, Torresc R, Joshid S, Shresthae R M, Yagnaramanf $\mathrm{M}$, et al. Impacts on household fuel consumption from biomass stove programs in India, Nepal, and Peru. Energy for Sustainable Development, 2013; 17(5): 403-411.

[27] Fiedler F. The state of the art of small-scale pellet-based heating systems and relevant regulations in Sweden, Austria and Germany. Renewable and Sustainable Energy Reviews, 2004; 8(3): 201-221.

[28] Zhang Z X, Zhang Y X, Zhou Y G, Riaz A, Crispin P P, Harold A, et al. Systematic and conceptual errors in standards and protocols for thermal performance of biomass stoves. Renewable and Sustainable Energy Reviews, 2017; 72: 1343-1354.

[29] Smith K R, Gu S H, Huang K, Qiu D X. One hundred million improved cookstoves in China: How was it done? World Development, 1993; 21(6): 941-961.

[30] The Environment Department (Climate Change), the World Bank. Household cookstoves, environment, health, and climate change: a new look at an old problem. World Bank, 2011.

[31] Kumar M, Kumar S, Tyagi S K. Design, development and technological advancement in the biomass cookstoves: A review. Renewable and Sustainable Energy Reviews, 2013; 26(10): 265-285.

[32] Mestl H E, Aunan K, Seip H M. Health benefits from reducing indoor air pollution from household solid fuel use in China-Three abatement scenarios. Environment International, 2007; 33(6): 831-840.

[33] Ministry of Agriculture of the People's Republic of China, General technical specification of domestic biofuel cooking stove. NY/T 2370-2013. Beijing, 2013. (in Chinese)

[34] Ministry of Agriculture of the People's Republic of China, Test performance method of domestic biofuel cooking stove. NY/T 2369-2013. Beijing, 2013. (in Chinese)

[35] Li N, Lu G, Li X L, Yan Y. Prediction of NOx emissions from a biomass fired combustion process based on flame radical imaging and deep learning techniques. Combustion Science and Technology, 2016; 188(2): 233-246.

[36] Rogge W F, Hildemann L M, Mazurek M A, Cass G R, Simoneit B R T. Sources of fine organic aerosol. 9. pine, oak, and synthetic log combustion in residential fireplaces. Environmental Science and Technology, 1998; 32(1): 13-32.

[37] Simoneit B R T. Biomass burning-a review of organic tracers for smoke from incomplete combustion. Applied Geochemistry, 2002; 17(3): 129-162.
[38] Zhang Y, Tong D, Song K Y. Study on biomass thermo-chemical conversion techniques. Forest Engineering, 2012; 28(2): 14-17. (in Chinese)

[39] Chomanee J, Tekasakul S, Tekasakul P, Furuuchi M, Otani Y. Effects of moisture content and burning period on concentration of smoke particles and particle-bound polycyclic aromatic hydrocarbons from rubber wood combustion. Aerosol Air Quality Research, 2009; 9(4): 404-411.

[40] Mcdonald J D, Zielinska B, Fujita E M, Sagebie J C, Chow J $\mathrm{C}$, Watson J G, et al. Fine particle and gaseous emission rates from residential wood combustion. Environmental Science and Technology, 2000; 34(11): 2080-2091.

[41] Bignal K L, Langridge S, Zhou J L. Release of polycyclic aromatic hydrocarbons, carbon monoxide and particulate matter from biomass combustion in a wood-fired boiler under varying boiler conditions. Atmospheric Environment, 2008; 42(39): 8863-8871.

[42] Huangfu Y B, Li H X, Chen X F, Xue C Y, Chen C, Liu G Q. Effects of moisture content in fuel on thermal performance and emission of biomass semi-gasified cookstove. Energy for Sustainable Development, 2014; 21(1): 60-65.

[43] Xie Q Q. Studies on the physical performance and combustion characteristic of the biomass densification briquetting fuel. Nanjing, Nanjing Forestry University, 2008. (in Chinese)

[44] Li S H. To investigate the control of nitrogen oxide emissions. North China Electric Power Technology, 2007; (S2): 1-4. (in Chinese)

[45] Shen G F, Wang S Y, Wei W, Zhang Y Y, Min Y J, Wang B, et al. Emission factors, size distributions, and emission inventories of carbonaceous particulate matter from residential wood combustion in rural China. Environmental Science and Technology, 2012; 46(7): 4207-4214.

[46] Shen G F, Yang Y F, Wang W, Tao S, Zhu C, Min Y J, et al. Emission factors of particulate matter and elemental carbon for crop residues and coals burned in typical household stoves in China. Environmental Science and Technology, 2010; 44(18): 7157-7162.

[47] Jetter J, Zhao Y, Smith K R, Khan B, Yelverton T, Decarlo P, et al. Pollutant emissions and energy efficiency under controlled conditions for household biomass cookstoves and implications for metrics useful insetting international test standards. Environmental Science and Technology, 2017; 46(19): 10827-10834.

[48] Jenkins B M, Jones A D, Turn S Q, Williams R B. Emission factors for polycyclic aromatic hydrocarbons from biomass burning. Environmental Science and Technology, 1996; 30(8): 2462-2469.

[49] Dhammapala R, Claiborn C, Corkill J, Gullett B. Particulate emissions from wheat and Kentucky bluegrass stubble burning in eastern Washington and northern Idaho. Atmospheric Environment, 2006; 40(6): 1007-1015. 